\title{
Comparison between General and Spinal Anesthesia for Changes of Core and Peripheral Body Temperature in Leg Surgery
}

\author{
Arash Peivandi Yazdii ${ }^{1}$, Mostafa Delshad $^{2}$, Leila Mashhadi ${ }^{3}$ and MehryarTaghavi Gilani ${ }^{4 *}$ \\ ${ }^{1}$ Department of anesthesiology, Lung Disease research center, Mashhad university of medical sciences, Iran \\ ${ }^{2}$ Department of Anesthesiologist, Lung Disease research center, Mashhad university of medical sciences, Iran \\ ${ }^{3}$ Department of anesthesiology, Lung Disease research center, Mashhad university of medical sciences, Iran \\ ${ }^{4}$ Department of anesthesiology, Lung Disease research center, Mashhad university of medical sciences, Iran
}

*Corresponding author: Mehryar Taghavi, Gilani, Lung Disease research center,

Mashhad university of medical sciences, Mashhad, Iran

Received Date: October 06, 2020

Published Date: November 24, 2020

\begin{abstract}
Introduction: The temperature changes in general and spinal anesthesia is still controversial and in this study is compared hypothermia in both groups.

Materials and Methods: In this double-blinded clinical trial, 60 patients under goinglegsurgery were divided into two groups. The peripheral, front alandtympanic membrane temperature was measured before the induction and every half an hour until the recovery in the spinal and general groups. The data were evaluated by SPSS v.16 and $\mathrm{p}<0.5$ was considered significant.

Result: The demographic data was not significantly different between thetwo groups. The prevalence of hypothermia in general and spinal anesthesia was $76.7 \%$ and $60 \%$, respectively. The frontal temperature was significantly different between the two groups only at first $30 \mathrm{~min}$ ( $p=0.02$ ). The core temperature was significantly different after the first hour until recovery between the two groups (p-value was $0.03,0.04$,and 0.03 at 60 min, $90 \mathrm{~min}$, and recovery, respectively) and there was more reduction in general anesthesia $\left(2.7^{\circ} \mathrm{Ccompared}\right.$ with $\left.2.2^{\circ} \mathrm{C}\right)$. No relationship was observed between age, weight, and ambient with frontal, and core temperature. Shiveringin general and spinal anesthesia was $46.6 \%$ and $13.3 \%$, respectively, which was not statistically different in spite of the clinical difference ( $\mathrm{p}=0.253)$

Final conclusion: Hypothermia was higher in general anesthesia after the first hour, which necessitated the need for monitoring of core temperature in the orthopedic surgeries lasting for more than half an hour. No significant relationship was observed between ambient and core temperature, but ambient changes were not too high in our study.
\end{abstract}

Keywords: Hypothermia; General anesthesia; Spinal anesthesia

\section{Introduction}

The most common in traoperative temperature disorder during surgery is unintended hypothermia, it's prevalence is $50 \%$ to $90 \%$ [1-4]. Hypothermia is the result of combining general anesthesia and exposure to the cold operation rooms. In general anesthesia, the threshold required for vasoconstriction and shivering is decreased by $2-3^{\circ} \mathrm{C}$. Thelargest primary cause of hypothermia in most patients is the redistribution of body temperature from center to the environment [5-7]. Neuraxial anesthesia also disturbs score and peripheral thermoregulation control, which is accompanied by hypothermia $[8,9]$. Postoperative hypothermiais associated with physiological adverse effects and postoperative complications. Several studies have proven that evenamild hypothermia (1.5 to $2^{\circ} \mathrm{C}$ ) causes adverse outcomes such as 3 -fold increase in cardiacmorbidity, 3-fold increase in wound infection, coagulopathy 
and more need for allogeneic transfusion, long recovery, and longer hospitalization [10-13]. Another complication of hypothermia is postoperative shivering, which can lead to many hemodynamic and metabolic effects. Shivering increases the consumption of tissue oxygen and, consequently, pulmonary minute ventilation, cardiac work, patient discomfort, and recovery time [14].

Body temperature monitoring should be performed during general anesthesia in the patients whose surgery lasts for more than $30 \mathrm{~min}$ and during the spinal anesthesia of more than $60 \mathrm{~min}$. Also, core body temperature should be maintained at about 36$37^{\circ} \mathrm{C}$. Forced air blanket has the best and most efficient eating and is associated with less cost and more safety during surgery $[15,16]$.

This study is aimed to examine and compare the changes of core and peripheral temperature in general and spinal anesthesia and also relationship between age, sex, operation duration, and ambient temperature with core temperature changes and postoperative shivering, which still has conflicting results in previous studies.

\section{Method and Materials}

After the approval of Vice Chancellor for Research of University of Medical Sciences and Local Ethics Committee, this doubleblinded randomized clinical trial was performed on 60 patients undergoing lower extremity surgery with ASA I, II. The patients with preoperativef ever $\left(\mathrm{T}>38^{\circ} \mathrm{C}\right)$, hypothermia $\left(\mathrm{T}<36.5^{\circ} \mathrm{C}\right)$, spinal anesthesia contraindication, addiction, sensitivity to studied medication, blood transfusion during surgery, and surgery duration of more than $120 \mathrm{~min}$ were excluded. After obtaining a written consent, the patients were randomly divided using arandom numbers table and sealede nvelope into two same groups, each with 30 patients.

After obtaining consent from the patients for spinal or general anesthesia and inclusion into the study, $5 \mathrm{ml} / \mathrm{kg}$ normal saline was injected into all the patients after venipuncture. The first group underwent spinal anesthesia with midline approach in the sitting position of L3-L4 or L4-L5 with the injection of 12-15 mg bupivacaine solution $0.5 \%$ as well as $25 \mu \mathrm{g}$ fentanyl and, then, the patients were returned to the supine position. The anesthesia level was measured by pinprick test and maintained at T8-T10. For hypotension (Bp $\downarrow>30 \mathrm{mmHg}$ or $\mathrm{SBP}<90 \mathrm{mmHg}$ ), $5-10 \mathrm{mg}$ ephedrine was injected. Brady cardia was defined as $\mathrm{HR}<50 \mathrm{bpm}$ and was treated with the intravenous injection of $0.5 \mathrm{mg}$ atropine.

In the second group general anesthesia induced with $3 \mu \mathrm{g} / \mathrm{kg}$ fentany l, $2 \mathrm{mg} / \mathrm{kg}$ propofo l, and $0.5 \mathrm{mg} / \mathrm{kg}$ atracurium. After the tracheal intubation, anesthesia maintained with propofo l $(100 \mu \mathrm{g} /$ $\mathrm{kg}), 50 \%$ oxygen, nitrous oxide, and fentany l $(50 \mu \mathrm{g})$ were used every half an hour.

The patients were monitored with heart rate, blood pressure, peripheral oxygen saturation, and ECG. The ambient, frontal, and tympanic membrane temperatures were evaluated before the induction of anesthesia, and the nevery $30 \mathrm{~min}$ until the end of surgery and transfer to the recovery room by a tympanicthermo meter device (Genius 2 Electronic Thermometer). The patients with general anesthesia in the recovery room and those with spinal anesthesia during the surgery and until transfer to the ward was evaluated for shivering incidence.

\section{Statistical analysis method}

The software used in this study was SPSS v.16 (Chicago, IL), and the significant level was considered less than 0.05.For the statistical analysis of the nominal qualitative variables, Chi-squaretest and Fisher's exact test were used. First, the quantitative variables were examined using normality test such as Kolmogorov-Smirnov test. For the quantitative variables, t-test or Mann-Whitney test were applied to compare both groups. In the evaluation of the changes during surgery, multiple measurement ANOVA was used in each group. In order to investigate the effect of the variables on body temperature changes, linear regression analysis was used.

\section{Result}

The demographic information of the patents, bleeding rate, and surgery duration are shown in Table [1] and no significant difference was observed between the two groups (Table 1).

Table 1: Demographic and surgical parameters in two groups.

\begin{tabular}{|c|c|c|c|}
\hline Parameters & Spinal Anesthesia Group & General Anesthesia Group & P-Value \\
\hline Sex (F/M) & 20 -Oct & $19-$-Nov & 0.39 \\
\hline Age (years) & $45.18 \pm 19.43$ & $41.09 \pm 18.82$ & 0.29 \\
\hline Weight (Kg) & $71.48 \pm 15.06$ & $67.74 \pm 12.1$ & 0.11 \\
\hline Bleeding (ml) & $96.05 \pm 95.3$ & $96.61 \pm 93.02$ & 0.36 \\
\hline Operation time (min) & $101.96 \pm 24.84$ & $108.54 \pm 31.99$ & \\
\hline
\end{tabular}

\section{Prevalence and rate of hypothermia}

Considering the temperature less than $36^{\circ} \mathrm{C}$ as hypothermia, the prevalence of hypothermia during the study was obtained $76.7 \%$ ( 23 out of 30 patients)in general anesthesia and, in the group with spinal anesthesia, was observed $60 \%$ (18 out of 30 patients). Temperature reduction in the general and spinal anesthesia groups was up to $2.7^{\circ} \mathrm{C}$ and $2.2^{\circ} \mathrm{C}$, in general and spinal anesthesia groups respectively. 


\section{Core and peripheral body temperature changes}

At the beginning of anesthesia, the average core body temperature in the regional and general anesthesia groups was equal to 36.67 and 36.40 , respectively. And also, the peripheral body(frontal) temperature in the regional and general anesthesia groups was 34.83 and 34.24 , respectively. No significant difference was observed between the two groups in terms of core and peripheral body temperatures at the beginning of the study and before the injection of the spinal or general anesthesia medication (p-value at peripheral and core temperatures was equal to 0.62 and 0.71 , respectively). The core and peripheral body temperature changes in the patients during the study are shown in [Table 2].

Table 2: core and peripheral body temperature in two groups on duration of surgery.

\begin{tabular}{|c|c|c|c|c|}
\hline Core and Peripheral Body Temperature & & Spinal Anesthesia Group & General Anesthesia Group & P-Value \\
\hline \multirow{5}{*}{ Core Temperature (Tympanic) $\circ \mathrm{C}$} & Before anesthesia & $36.67 \pm 1$ & $36.4 \pm 1.08$ & 0.71 \\
\hline & $30 \mathrm{~min}$ & $36.22 \pm 0.86$ & $35.08 \pm 0.84$ & 0.23 \\
\hline & $60 \mathrm{~min}$ & $36 \pm 1.01$ & $35.58 \pm 0.93$ & 0.038 \\
\hline & $90 \mathrm{~min}$ & $36.13 \pm 0.85$ & $35.52 \pm 0.95$ & 0.392 \\
\hline & Recovery time & $36.7 \pm 0.95$ & $35.24 \pm 1.4$ & 0.732 \\
\hline \multirow{5}{*}{ Peripheral Temperature (Frontal) $\circ \mathrm{C}$} & Before anesthesia & $34.83 \pm 0.95$ & $34.24 \pm 1.31$ & 0.62 \\
\hline & $30 \mathrm{~min}$ & $34.17 \pm 1.05$ & $33.74 \pm 1.02$ & 0.02 \\
\hline & $60 \mathrm{~min}$ & $33.88 \pm 1.08$ & $33.63 \pm 1.4$ & 0.382 \\
\hline & $90 \mathrm{~min}$ & $33.86 \pm 1.1$ & $33.74 \pm 1.51$ & 0.392 \\
\hline & Recovery time & $33.85 \pm 1.06$ & $33.8 \pm 0.91$ & 0.71 \\
\hline
\end{tabular}

In the comparison of patients' peripheral body temperature at

At other minutes, no significant difference was observed between different minutes, the significant difference was only observed at the two groups [Figure 1]. 30 min between the general and spinal anesthesia groups $(\mathrm{P}=0.02)$.

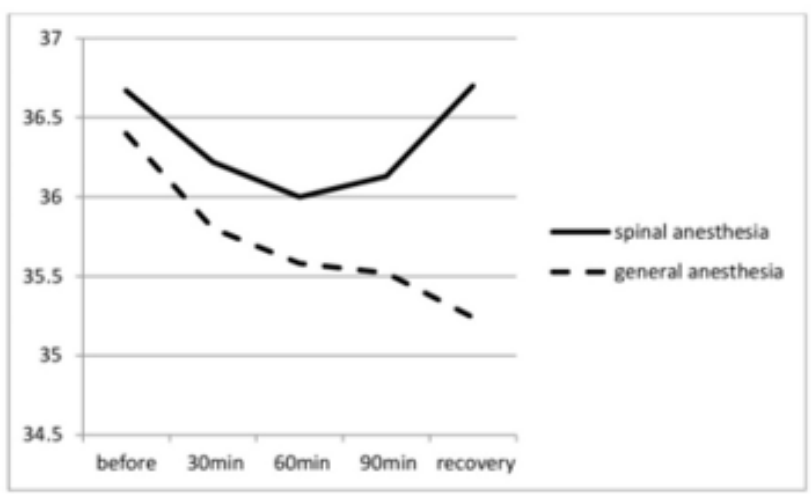

Figure 1: Comparison of central body temperature (tympanic membrane).

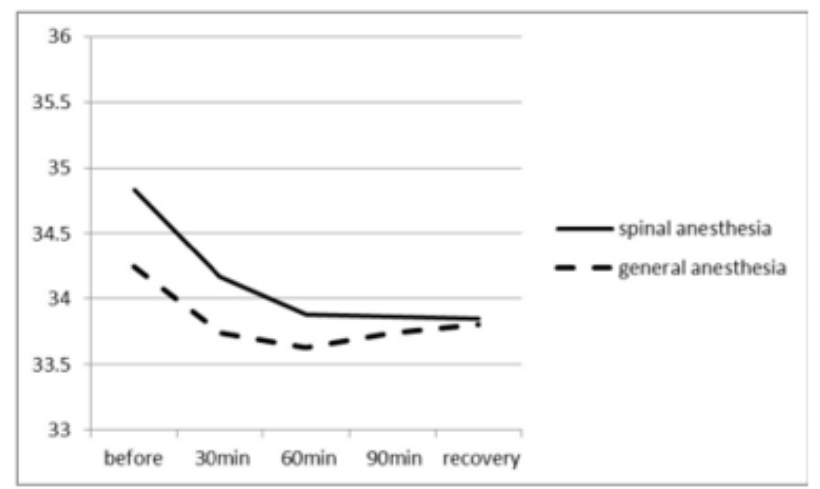

Figure 2: Comparison of peripheral body temperature (frontal skin surface). 
In the comparison of core body temperature, no significant difference was found up to $30 \mathrm{~min}(\mathrm{p}=0.20)$. Butlater, duringthe study, the core temperature difference was increased between the two groups and this difference was statistically significant ( $p$-value was $0.03,0.04$,and0.03at60 $\mathrm{min}, 90 \mathrm{~min}$, and recovery time, respectively) [Figure 2].

\section{Effective factors for hypothermia during surgery}

There was no significantrelationship between ambient and peripheral (frontal) body temperatures during the surgery in spinal anesthesia (at 30, 60,and90 $\mathrm{min}$ as well as recovery time, p-value was $0.34,0.15,0.24$, and 0.14 , respectively). Also, no significant relationship was found between ambient temperature and core body (tympanic) temperature (at 30,60 , and $90 \mathrm{~min}$ as well as recovery time, p-value was $0.13,0.59 \backslash, 0.43$, and 0.096 , respectively). In general anesthesia, there was no significant relationship between ambient temperature and peripheral body (frontal) temperature (at minutes 30, 60, and90as well as recovery time, p-value was 0.09, $0.06,0.17$, and 0.72 , respectively)and no significant relationship was found between ambient temperature and core body (tympanic) temperature (at minutes30, 60, and 90 as well as recovery time, $\mathrm{p}$-value was $0.82,0.45,0.60$, and 0.76 , respectively). Also, the other risk factors such as age and weight, no significant relationship was observed between the two groups. During the surgery, there was no significant relationship between mean arterial pressure changes and core body (tympanic) temperature (at minutes30, 60, and 90 as well as recovery time, p-value was $0.93,0.98,0.50$, and 0.50 , respectively).

\section{Shivering during and after surgery}

The incidence of shivering in the spinal anesthesia was 13.33\% (4 cases)during the study; in shivering patients, the average operating time was113.0min and, in non-shivering cases, the average operating time was $100.0 \mathrm{~min}$.But, the difference was not statistically different $(p=0.253)$.The incidence of shivering in the general anesthesia group was observed in $46.66 \%$ (14 cases)during the study and, in shivering patients, the average operating time was $115.3 \mathrm{~min}$ and in non-shivering patients was $102.18 \mathrm{~min} . \mathrm{But}$, the difference was not statistically significant $(p=0.259)$. In this study, no statistically significant relationship was observed between the incidence of shivering and core body temperature in both groups $(\mathrm{p}=0.41)$.

\section{Discussion}

In traoperative hypothermia is a common issue after general or regional anesthesia and its prevention requires the attention of anesthetists as well as cooperation of surgeons and operating room personnel.

The prevalence of hypothermia in several studies has been reported up to $90 \%$. In this study, in the general anesthesia group and in the spinal anesthesia group, the prevalence of hypothermia during recovery was $76.7 \%$ and $60 \%$, respectively. The rate of temperature duction in the general and spinal anesthesia groups was observed up to $2.7^{\circ} \mathrm{C}$ and $2.2^{\circ} \mathrm{C}$, respectively.

In this study, the core temperature reduction in the general anesthesia group was more significant than the spinal anesthesia group. In the general anesthesia group, the core body temperature was decreased on average from $36.4^{\circ} \mathrm{C}$ at the beginning of surgery to $35.2^{\circ} \mathrm{C}$ in recovery (the average decrease of $1.2^{\circ} \mathrm{C}$ and maximum decrease of $2.7^{\circ} \mathrm{C}$ ). In the spinal anesthesia group, at the first hour, the core temperature was decreased on average from 36.7 to $36^{\circ} \mathrm{C}$ (average of $0.7^{\circ} \mathrm{C}$ and maximum of $2.2^{\circ} \mathrm{C}$ ); but then, it was increased again and reached $36.7^{\circ} \mathrm{C}$.This temperature difference between the general and spinal anesthesia groups was significant after the first hour. According to different studies, the core temperature decrease during general anesthesia at the first hour, due to their distribution of temperature and dysregulation of the core temperature and vasodilation after anesthetic drugs, has been observedat $0.5-1.5^{\circ} \mathrm{C}$ $(2,5) . I n$ this study, in the general anesthesia, the average decrease of temperature at the first hour was $0.8^{\circ} \mathrm{C}$ (from 36.4 to35.6), and the average temperature decrease was less as the surgery continued $\left(0.4^{\circ} \mathrm{C}\right)$. In spinal anesthesia, according to some studies, the core temperature decrease is reported to be similar to general anesthesia, due to the anesthesia and disruption in lower extremity; even sometimes higher temperature decrease is observed $(17,18)$. In other studies, the decreased core temperature in spinal anesthesia has been reported to be less than general anesthesia $(19,20)$.In the present work, core temperature in the spinal anesthesia at the first hour was decreasedless than the general anesthesia, but in the spinal anesthesia, there was no higher temperature reduction and even the core temperature was increased and returned to its initial rate. Both general and spinal anesthesia changed the function of the autonomic nervous system in the body, which had a great impact on the regulation of body temperature. In general anesthesia, the effect of anesthetics on the central nervous system disrupted the regulation power of central temperature through inhibiting the hypothalamic system. In contrast, in the spinal anesthesia, the central nervous system was not affected. The relative inhibition of central regulation response against peripheral regulation system might explain better maintenance of the central temperature in the spinal anesthesia group.

The age of more than 60 , low body weight, poor nutrition, disturbing conditions for thermoregulation (diabetic poly neuropathy, hypothyroidism, and consumption of sedatives or psychedelic drugs), higher class of ASA I, preoperative hypothermia, combination of general and spinal anesthesia, operation time over $2 \mathrm{~h}$, and infusion of a large volume of fluids or cold blood increase the risk of hypothermia $[8,16-17]$. 
The temperature of operation room, especially when being less than $21^{\circ} \mathrm{C}$, has an effect onpostoperative body temperature in patients. Hence, the minimum operation room temperature of $21^{\circ} \mathrm{C}$ and $24^{\circ} \mathrm{C}$ is recommended for adults and children, respectively. It has been reported in previous studies that ambient temperature can affect the body temperature and increase the core temperature reductionin the patients with general anesthesia, especially because surgeons can work easily in cooler environment $(8,21)$ and also warmer environment facilitates the maintenance of core body temperature. The effect of ambient temperature on the body temperature of patients has not been clearlydescribed. In Goldberg's study on 101 patients with inhalation anesthesia, ambient temperature had no effect on body temperature (22). Morris et al. defined the temperature of $21^{\circ} \mathrm{C}$ as the critical temperature for operation rooms and showed that at the ambient temperature ofmore than $21^{\circ} \mathrm{C}$, the body temperature did not change during general anesthesia (23).Stevens et al. also demonstrated that the ambient temperature of $21^{\circ} \mathrm{C}$ was enough to maintain the body temperature during epidural anesthesia, but a warmer environment was required to maintain the core temperature in general anesthesia [24].

In 2000, Gamal et al. showed that the operation room temperature had an effect on the postoperative body temperature of patients (25). In the present study, the ambient temperature in general and spinal anesthesia was from25.8to 25.9 and from 24.9to25.6, respectively, and there was no temperature difference between the two groups. Also, no significant temperature reduction was observed in the operating room. In the present investigation, no relationship was observed between ambient and core temperature, which might be related to lack of significant temperature change in the operating environment.

In the elderly patients, the maintenance power of core body temperature was even decreased in the awakened people. Some inconsistent results have been obtained in the results and aging is in conflict with temperature regulation or has no effect. However, in most studies, age range is wide and not limited to old age. In the present study, age and weight had no significant effect on core and peripheral body temperature changes of the patients.

Postoperative shivering occurs in $10 \%$ to $60 \%$ of the patients after general and regional anesthesia [26], respectively, and treated by active warming and drugs such aspethidine and tramadol. This complication depends on age, sex, anesthetics, and surgery type [27]. The prevalence of postoperative shivering in this study was $46.7 \%$ in the general anesthesia group and $13.37 \%$ in thespinal anesthesia group; it was 3.5 times higher in spinal than general anesthesia groups. In this study, there was no significant relationship between surgery duration, core body temperature, and shivering rate.
In conclusion, in traoperative hypothermia is common and $76.7 \%$ and $60 \%$ in general and spinal anesthesia respectively. Core temperature reduced after 1 hour in general anesthesia, but not in spinal anesthesia. There was not relationship between core temperature with ambient temperature, age and weight in this study.

\section{Acknowledgement}

None.

\section{Conflicts of Interest}

No conflicts of interest.

\section{References}

1. Burns SM, Piotrowski K, Caraffa G, Wojnakowski M (2010) Incidence of postoperative hypothermia and the relationship to clinical variables. J Perianesth Nurs 25(5): 286-289.

2. Andrzejowski J, Hoyle J, Eapen G, Turnbull D (2008) Effect of prewarming on post-induction core temperature and the incidence of inadvertent perioperative hypothermia in patients undergoing general anaesthesia. Br J Anaesth 101(5): 627-631.

3. Burger L, Fitzpatrick J (2009) Prevention of inadvertent perioperative hypothermia. Br J Nurs 18(18): 1116-1119.

4. Tappen RM, Andre SP (1996) Inadvertent hypothermia in elderly surgical patients. AORN J 63(3): 639-644.

5. Kurz A (2008) Physiology of thermoregulation. Best Pract Res Clin Anaesthesiol. 22(4): 627-644.

6. Sessler DI (2000) Perioperative heat balance. Anesthesiology 92(2): 578-596.

7. Sessler DI (2009) New surgical thermal management guidelines. Lancet 374(9695): 1049-1050.

8. Frank SM, El-Rahmany HK, Cattaneo CG, Barnes RA (2000) Predictors of hypothermia during spinal anesthesia. Anesthesiology 92(5): 13301334

9. Roe CF, Cohn FL (1972) The causes of hypothermia during spinal anesthesia. Surg Gynecol Obstet 135(4): 577-580.

10. Frank SM, Fleisher LA, Breslow MJ, Higgins MS, Olson KF, et al. (1997) Perioperative maintenance of normothermia reduces the incidence of morbid cardiac events. A randomized clinical trial. JAMA 277(14): 11271134

11. Schmied H, Kurz A, Sessler DI, Kozek S, Reiter A (1996) Mild hypothermia increases blood loss and transfusion requirements during total hip arthroplasty. Lancet 347(8997): 289-292.

12. Forbes SS, Stephen WJ, Harper WL, Loeb M, Smith R, et al. (2008) Implementation of evidence-based practices for surgical site infection prophylaxis: results of a pre- and postintervention study. J Am Coll Surg 207(3): 336-341.

13. Bush HL, Hydo LJ, Fischer E, Fantini GA, Silane MF, et al. (1995) Hypothermia during elective abdominal aortic aneurysm repair: the high price of avoidable morbidity. J Vasc Surg 21(3): 392-400.

14. Horn EP (1999) Postoperative shivering: aetiology and treatment. Curr Opin Anaesthesiol 12(4): 449-53.

15. Hart SR, Bordes B, Hart J, Corsino D, Harmon D (2011) Unintended perioperative hypothermia. Ochsner J Fall 11(3): 259-270.

16. Moola S, Lockwood C (2011) Effectiveness of strategies for the management and/or prevention of hypothermia within the adult perioperative environment. Int J Evid Based Health 9(4): 337-345. 
17. Holdcroft A, Hall GM, Cooper GM (1979) Redistribution of body heat during anaesthesia. A comparison of halothane, fentanyl and epidural anaesthesia. Anaesthesia 34(8): 758-764.

18. Jenkins J, Fox J, Sharwood-Smith G (1983) Changes in body heat during transvesical prostatectomy. A comparison of general and epidural anaesthesia. Anaesthesia 38(8): 748-753.

19. Hendolin H, Lansimies E (1982) Skin and central temperatures during continuous epidural analgesia and general anaesthesia in patients subjected to open prostatectomy. Ann Clin Res 14(4):181-186.

20. Frank SM, Beattie C, Christopherson R, Norris EJ, Rock P, et al (1992) Epidural versus general anesthesia, ambient operating room temperature, and patient age as predictors of inadvertent hypothermia. Anesthesiology 77(2): 252-257.

21. Slotman GJ, Jed EH, Burchard KW (1985) Adverse effects of hypothermia in postoperative patients. Am J Surg 149(4): 495-501.

22. Goldberg MJ, Roe CF 91966) Temperature changes during anesthesia and operations. Arch Surg 93(2): 365-369.
23. Morris RH, Wilkey BR (1970) The effects of ambient temperature on patient temperature during surgery not involving body cavities. Anesthesiology 32(2): 102-107.

24. Stevens MF, Werdehausen R, Hermanns H, Lipfert P. Skin temperature during regional anesthesia of the lower extremity. Anesth Analg 102(4): $1247-1251$

25. El-Gamal N, El-Kassabany N, Frank SM (2000) Age-related thermo -regulatory differences in a warm operating room environment. Anesth Analg 90: 694-698.

26. Yared JP, Starr NJ, Hoffmann-Hogg L, Bashour CA, Insler SR, et al. (1998) Dexamethasone decreases the incidence of shivering after cardiac surgery: a randomized, double-blind, placebo-controlled study. Anesth Analg 87(4): 795-799.

27. Eberhart LH, Doderlein F, Eisenhardt G, Kranke P, Sessler DI, et al. (2005) Independent risk factors for postoperative shivering. Anesth Analg 101(6): 1849-1857. 